\title{
Review Article \\ Dispersive Liquid-Liquid Microextraction in the Analysis of Milk and Dairy Products: A Review
}

\author{
Andrew Quigley, Wayne Cummins, and Damian Connolly \\ Pharmaceutical and Molecular Biotechnology Research Centre, Department of Science, Waterford Institute of Technology, \\ Waterford, Ireland
}

Correspondence should be addressed to Damian Connolly; drdamianconnolly@outlook.com

Received 26 August 2016; Accepted 10 October 2016

Academic Editor: Victor David

Copyright (C) 2016 Andrew Quigley et al. This is an open access article distributed under the Creative Commons Attribution License, which permits unrestricted use, distribution, and reproduction in any medium, provided the original work is properly cited.

\begin{abstract}
Dispersive liquid-liquid microextraction (DLLME) is an extraction technique developed within the last decade, which involves the dispersion of fine droplets of extraction solvent in an aqueous sample. Partitioning of analytes into the extraction phase is instantaneous due to the very high collective surface area of the droplets. This leads to very high enrichment factors and very low solvent consumption, relative to other liquid or solid phase extraction methods. A comprehensive review of the various modes of DLLME in the analysis of organic and inorganic analytes in dairy products (milk, cheese, infant formula, yogurt, and breast milk) is presented here. Dairy products present a complex sample matrix and the removal of interfering matrix components can prove troublesome. This review focuses on sample pretreatment prior to the appropriate DLLME procedure, the extraction and dispersive solvents chosen, derivatisation methods, and analytical figures of merit. Where possible, a critical comparison of DLLME methods has been undertaken. The overall suitability, and limitations, of DLLME as a sample preparation technique for dairy products has been assessed.
\end{abstract}

\section{Introduction}

One of the most important steps in any analytical procedure is the extraction and clean-up of the sample in question. There are a variety of methods that perform these tasks, such as liquid-liquid extraction (LLE) [1] and solid phase extraction (SPE) [2]. While these methods perform the above tasks adequately, they also suffer a number of drawbacks. Both LLE and SPE are environmentally unfriendly due to the large amounts of organic solvents used, they are slow, and labour intensive. The use of an SPE method also requires the purchase of solid phase extraction cartridges.

The development of microextraction techniques has gone some way to resolving some of these problems. Solid phase microextraction (SPME) was first developed in 1990 [3] and has been used extensively for a range of analytes (triazines from water [4], cephalosporins from milk [5], and short chain fatty acids from rat faeces [6]). Although SPME is more environmentally friendly than LLE and SPE as the technique does not require solvents, it still presents considerable disadvantages. The SPME fibres have a limited lifetime and are expensive and sample carryover can be an issue.

Liquid phase microextraction (LPME) offers an alternative to SPME. LPME can be divided into three classes: single drop liquid phase microextraction (SD-LPME) [7], hollow fibre liquid phase microextraction (HF-LPME) [8], and dispersive liquid-liquid microextraction (DLLME) [9]. All three forms of LPME are environmentally friendly since the volume of organic solvent used is typically in the microliter range. These methods do not have the high cost and sample carryover problems associated with SPME. Even though SDLPME vastly reduces the volume of organic solvent used, there are other intrinsic problems with this method. Excessive stirring tends to break up the droplet, the extraction is time consuming, and reaching equilibrium can often prove challenging [10]. The development of HF-LPME [8] provides a way to stabilise the extraction droplet in SD-LPME by placing it in a hollow fibre but in general the method still 


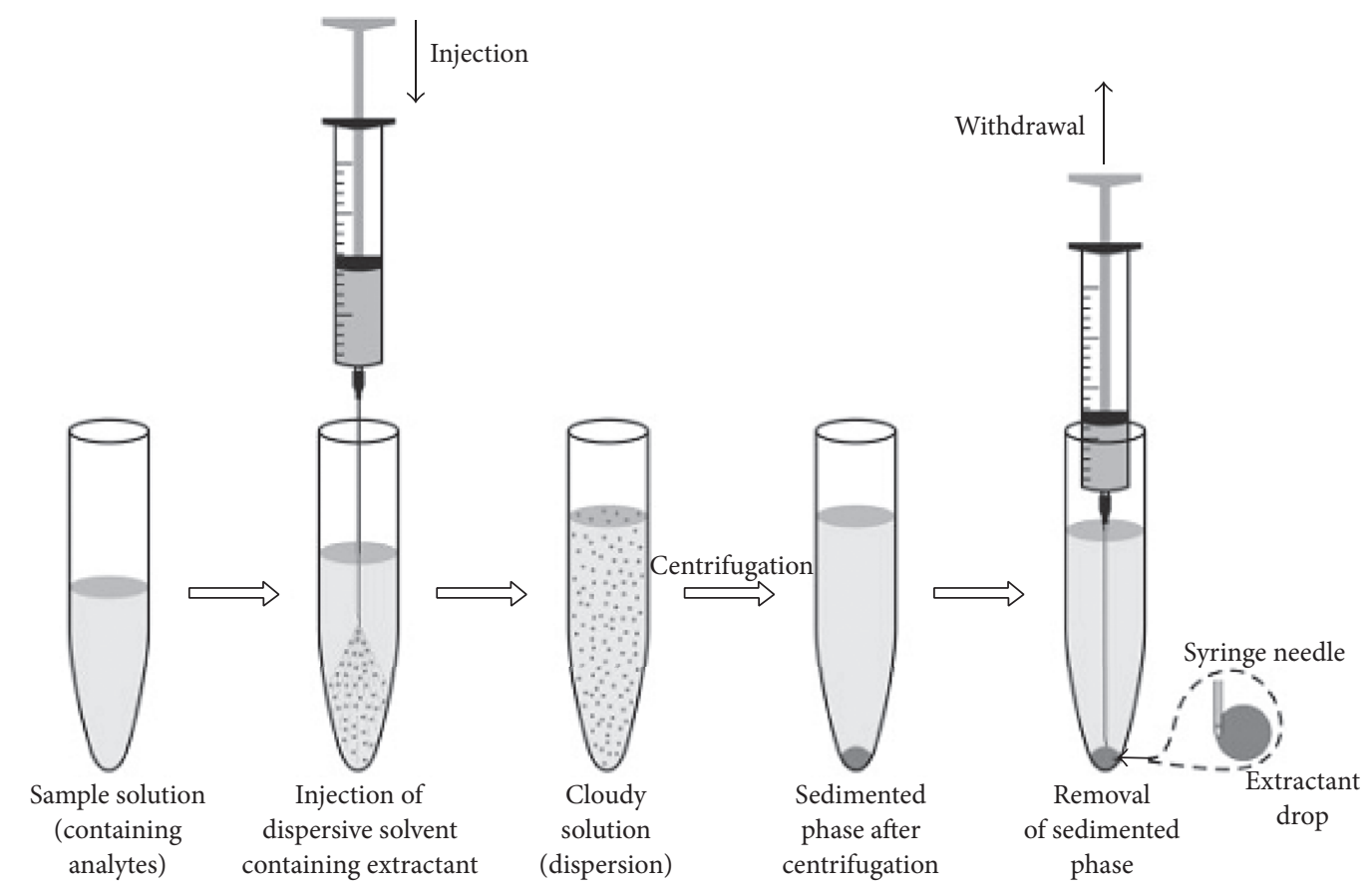

FIgURE 1: Schematic of DLLME technique [9].

requires long extraction times of at least 20 minutes [11] although methods have been reported using extraction times as low as eight minutes [12]. DLLME is the latest development in LPME and is discussed in more detail below.

\section{Principles of DLLME}

In a typical DLLME protocol, an extraction solvent is mixed with a dispersive solvent and this solvent mixture is then rapidly injected into the aqueous sample. The rapid injection of the extraction-dispersive solvent mixture produces a cloudy solution, formed of microdroplets of extraction solvent dispersed in the aqueous sample as shown in Figure 1. The formation of a cloudy solution/emulsion allows for the instantaneous partitioning of analytes from the aqueous sample into the extraction phase (a major advantage of this technique). This is achieved by the large surface area relative to LLE created by the numerous microdroplets. The cloudy solution is then centrifuged which breaks the emulsion into a two-phase system allowing for easy recovery of the extraction solvent for analysis.

There are several requirements that must be fulfilled in order for DLLME to be successful. The extraction solvent must be immiscible with water and miscible with the dispersive solvent and show a high affinity for the target analytes. In what will be referred to hereafter as "traditional DLLME," the extraction solvent is typically denser than water such that it will form a "sedimented phase" upon centrifugation for easy collection with a fine syringe needle. Conversely, the dispersive solvent has to be miscible with both the extraction solvent and the aqueous sample. Ideally, the extraction solvent will be compatible with the analytical technique being used; otherwise evaporation of the extraction solvent and reconstitution in an appropriate solvent is required. Alternatively, in-syringe back extraction could be used to extract the analytes into a compatible solvent [38]. Prior to analysis, the volume and type of extraction and dispersive solvent, ionic strength, $\mathrm{pH}$ of the aqueous phase, extraction time, and centrifugation time must be optimised to ensure quantitative extraction of analytes.

An efficient DLLME method is characterised by a high enrichment factor (EF) and high relative recovery (RR). Enrichment factor (EF) is calculated as shown in (1), where $C_{0}$ represents the concentration of the analyte in the original sample and $C_{\text {sed }}$ represents the concentration of the analyte in the sedimented extraction solvent.

$$
\text { Enrichment factor }=\frac{C_{\text {sed }}}{C_{0}} .
$$

The RR is calculated according to (2), where $C_{\text {found }}$ shows total amount of analyte found after addition of standard, $C_{\text {real }}$ is the original concentration of analyte in the sample, and $C_{\text {add }}$ is the amount of standard that was spiked into the original sample.

$$
\text { Relative recovery }=\frac{C_{\text {found }}-C_{\text {real }}}{C_{\text {add }}} \times 100 \text {. }
$$

\section{Alternative Modes of DLLME}

Recently, low-density solvents have been used as extraction solvents in DLLME in order to increase the range of extraction solvents compatible with the method. This mode is called low-density solvent based DLLME (LDS-DLLME) [39] and the extraction solvent (including toluene, xylene, hexane, and 


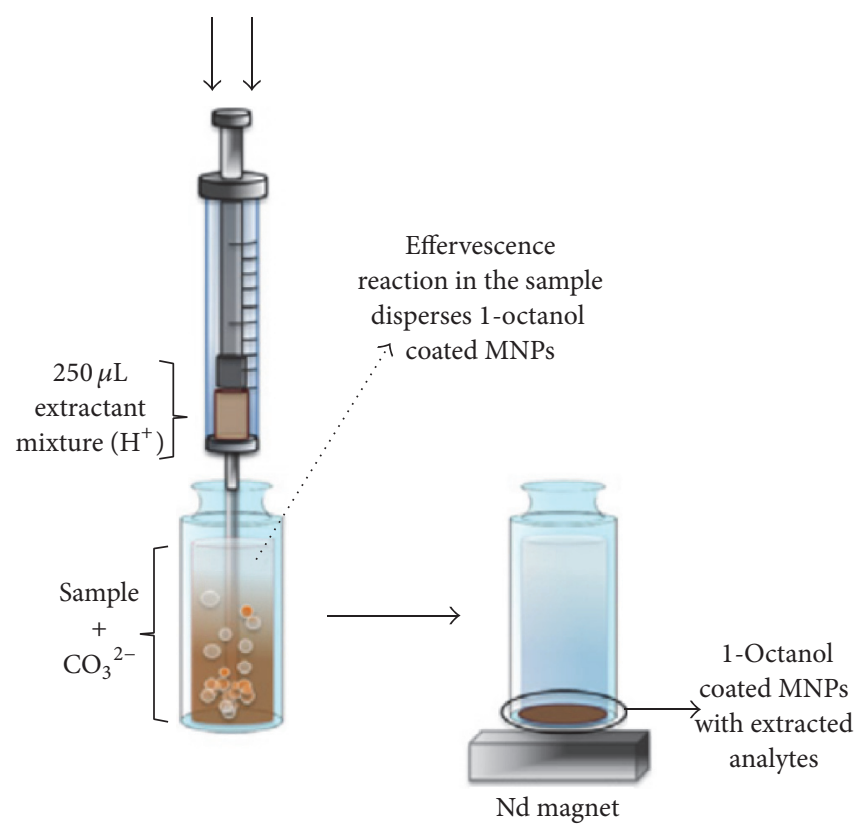

(a)

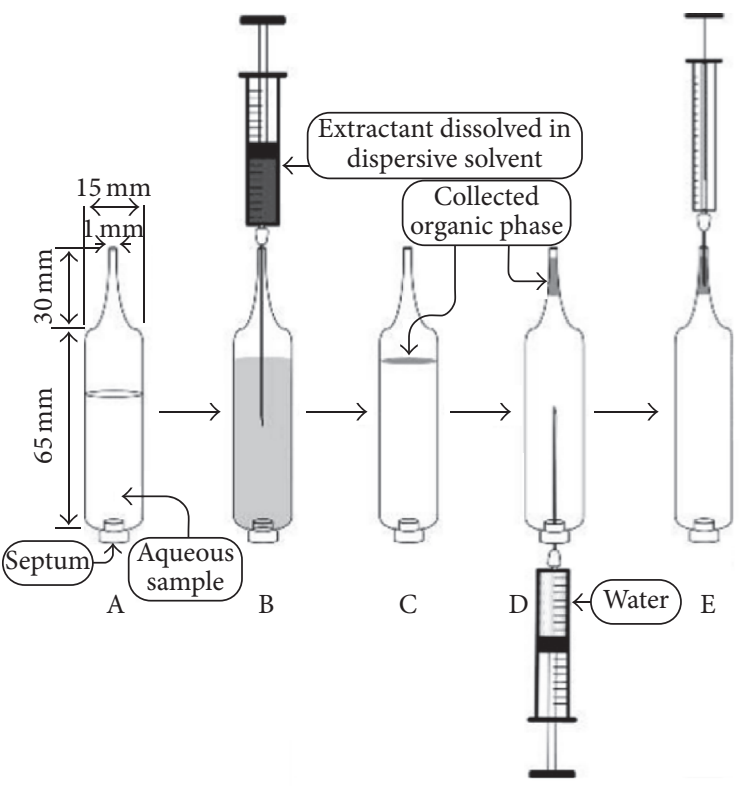

(b)

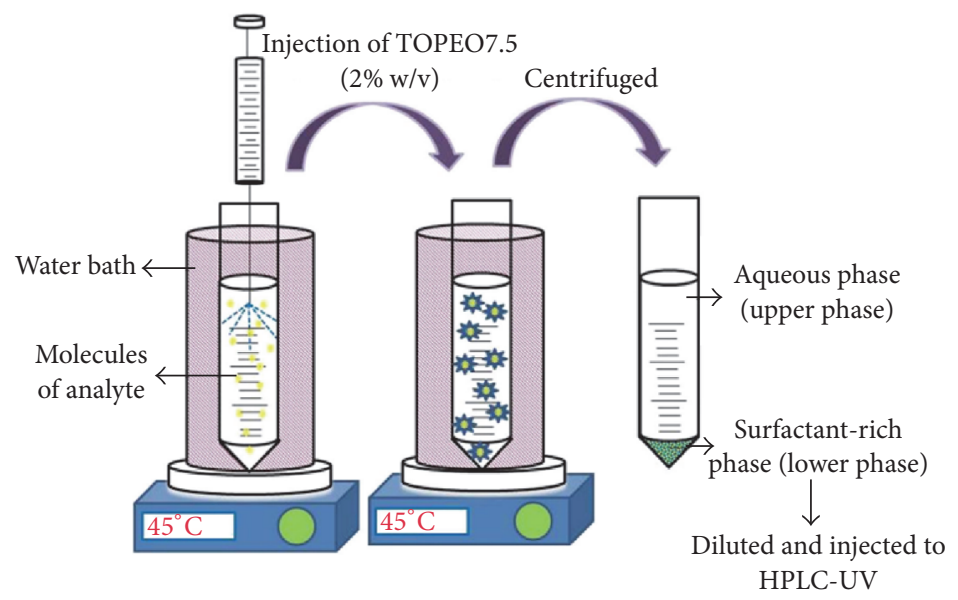

(c)

Figure 2: Schematic diagram of (a) effervescence DLLME [46], (b) LDS-DLLME using specialist glassware [52], and (c) CP-DLLME [48].

heptane) floats on the surface of the aqueous phase after phase separation is induced. The solvent is recovered using a fine needle and this process is simplified when specialist glassware or other vessels are used to trap the floating solvent in a narrow restriction in the vessel [40] as shown in Figure 2(b). An advantage of LDS-DLLME is that, after centrifugation, any matrix components will be sedimented at the bottom of the extraction vessel while the extraction solvent will be floating on top. This will lead to a cleaner extract and potentially cleaner chromatography [41].

Solidified floating organic drop DLLME (SFO-DLLME) was developed by Melwanki et al. [38, 39] and involves the use of low-density extraction solvents having a melting point close to room temperature (typically 1-undecanol or 1-dodecanol). After phase separation the floating extraction solvent is frozen by placing the vessel on ice after which the frozen drop is easily collected into a separate vessel where it is usually diluted with a chromatographically suitable solvent prior to analysis [42]. While the use of a less toxic extraction solvent is advantageous, the choice of extraction solvent is limited to those that have a melting point at approximately room temperature [43].

Additional modifications to DLLME methods include the elimination of time-consuming centrifugation steps via the use of a deemulsification solvent which causes phase separation of the emulsion upon its addition [41]. Seebunrueng et al. have reported a similar method whereby the addition of a salt $\left(\mathrm{AlCl}_{3}\right)$ is used to induce phase separation due to a disruption of the interfacial tension at the droplet surface [44]. Alternative methods have also been developed to enhance the dispersion of the extraction solvent throughout the aqueous sample. The use of ultrasound, vortex, or manual shaking will 
increase the number of microdroplets of extraction solvent resulting in an even larger surface area [45]. Effervescence assisted DLLME involves the in situ generation of bubbles of $\mathrm{CO}_{2}$ to assist the dispersion of the extraction solvent, removing a need for the dispersive solvent. The $\mathrm{CO}_{2}$ is produced by adding a mixture of sodium carbonate and a weak acid (citric acid), usually in the form of a pressed tablet $[44,46]$. This technique allows for the reduction in the use of organic solvents, potentially lowering the cost of the overall analysis.

Air assisted dispersive liquid-liquid microextraction (AA-DLLME) removes the need for a dispersive solvent by repeatedly aspirating the aqueous phase and the extraction solvent into a glass syringe until a cloudy solution is formed [40]. Methods to allow easier recovery of the extraction solvent have also been developed. Hydrophobic magnetic nanoparticles interact with the extraction phase and can be sedimented by applying a magnet; this eliminates the centrifugation step [47]. The use of magnetic nanoparticles has also been combined with effervescence assisted dispersion, mentioned above [46]. A schematic of this method can be seen in Figure 2(a).

Surfactant assisted DLLME (SA-DLLME) uses surfactants as dispersive solvents [34] whereas cloud point DLLME (CP-DLLME) uses surfactants as an extraction solvent to produce a surfactant rich sedimented phase after centrifugation [48]. Specifically, it involves heating the sample solution containing the appropriate surfactant past its cloud point. The cloud point is defined as the temperature at which phase separation occurs and the analytes are extracted into the surfactant rich phase as shown in Figure 2(c). Ionic liquids have been used as an alternative to traditional organic extraction solvents in ionic liquid DLLME (IL-DLLME) because they have tuneable physicochemical properties. For example, ionic liquid miscibility in either water or organic solvents can be controlled by selecting the appropriate anion/cation combination and by incorporating the proper functional group within the IL. In addition, they exhibit lower toxicity than organic extraction solvents [49]. Ionic liquids have also been used as both dispersive and extraction solvents in combination with ultrasound assisted dispersion, referred to as ultrasound assisted ionic liquid/ionic liquid DLLME (UAIL/IL-DLLME) [29]. In an effort to improve selectivity for polar or acidic/basic analytes, $\mathrm{pH}$-controlled DLLME $(\mathrm{pH}-$ DLLME) has also been developed [50]. By performing two DLLME procedures it is possible to remove matrix interferences in the first extraction step, followed by a back extraction after appropriate $\mathrm{pH}$ adjustment.

\section{Modes of DLLME Used in Dairy Analysis}

4.1. Traditional DLLME. Prior to a DLLME procedure on a complex matrix such as milk, lipids and proteins must be eliminated since they can act like surfactants and disrupt the interfacial tension at the droplet surface, hindering phase separation [51]. A list of sample pretreatment procedures, extraction solvent type and volume, dispersive solvent type and volume, analytical method used, and analytical figures of merit can be found in Table 1. One of the first reports of traditional DLLME used to extract analytes from dairy products was in 2009 by Daneshfar et al. [19] who extracted cholesterol in several food samples (egg yolk, milk, and olive oil). Previously centrifuged milk samples were subjected to acetonitrile precipitation to eliminate proteins and the aqueous supernatant (after further centrifugation) was subjected to a DLLME protocol. Acetone, ethanol, and acetonitrile were trialled as dispersive solvents using carbon tetrachloride as extraction solvent. Ethanol $(0.8 \mathrm{~mL})$ resulted in highest recoveries for cholesterol; lower and higher volumes resulted in either unstable emulsions or higher solubility of cholesterol in water, respectively. Four extraction solvents (carbon disulphide, dichloromethane, chloroform, and carbon tetrachloride) were tested but only carbon tetrachloride $(35 \mu \mathrm{L})$ yielded stable suspensions with ethanol. An extraction $\mathrm{pH}$ of 8.5 maximised recovery and partition of cholesterol was also deemed instantaneous upon generation of the stable emulsion (i.e., extraction time was several seconds). Nonaqueous reversed phase HPLC was used to quantify the analyte; because of poor chromatographic behaviour carbon tetrachloride extracts were evaporated to dryness and reconstituted in ethanol for injection. The method proved linear in the range $0.03-10 \mu \mathrm{g} \cdot \mathrm{L}^{-1}$ and the LOD was $0.01 \mu \mathrm{g} \cdot \mathrm{L}^{-1}$ representing detection limits 100 times lower than previously reported methods for cholesterol determination in milk.

Later in 2011 Farajzadeh et al. used DLLME for the extraction and preconcentration of triazole pesticides from milk samples [20], using GC-FID and GC-MS to quantify the analytes. Proteins were precipitated using both acetonitrile precipitation and $\mathrm{NaCl}$ salting out and the pesticides were preconcentrated from $1.0 \mathrm{~mL}$ of the ACN supernatant by adding $40 \mu \mathrm{L}$ of chloroform and rapidly injecting the mixture into $5 \mathrm{~mL}$ of deionized water. After a 5 -minute centrifugation at 4,000 rpm, enrichment factors of 156 (penconazole), 166 (hexaconazole), 180 (tebuconazole), 243 (triticonazole), and 387 (difenconazole) were achieved. The linear range was as wide as $20-80,000 \mu \mathrm{g} \cdot \mathrm{L}^{-1}$ for penconazole and hexaconazole and the lowest recorded LOD value was $4 \mu \mathrm{g} \cdot \mathrm{L}^{-1}$ for hexaconazole.

That same year, Liu et al. combined SPE and DLLME to enable the determination of 14 different polychlorinated diphenyls (PCDEs) and polybrominated diphenyl ethers (PBDEs) in milk using GC-MS [24]. To precipitate proteins, $50 \% \mathrm{NaOH}$ and acetone were added and the samples were heated at $70^{\circ} \mathrm{C}$ in a water bath. Afterwards, the analytes were extracted into $5 \mathrm{~mL}$ of hexane, dried over anhydrous sodium sulphate, and concentrated to $2 \mathrm{~mL}$ by evaporation before loading onto the SPE column. The resulting fractions from SPE were dried and reconstituted in $1 \mathrm{~mL}$ of acetone, which was used as the dispersive solvent in the optimised DLLME procedure. Chlorobenzene $(19 \mu \mathrm{L})$ was mixed with the dispersive solvent and rapidly injected into $5 \mathrm{~mL}$ of Milli$\mathrm{Q}$ water. The developed SPE-DLLME procedure proved to be effective since the sample matrix did not have a significant impact on extraction efficiencies. The method provided good recoveries and \%RSD values for both polychlorinated diphenyls (recovery: 100.0-131.8\%; precision: $3.20-10.20 \%$ ) and polybrominated diphenyl ethers (recovery: $74.0-93.6 \%$; $1.12-12.34 \%)$. 


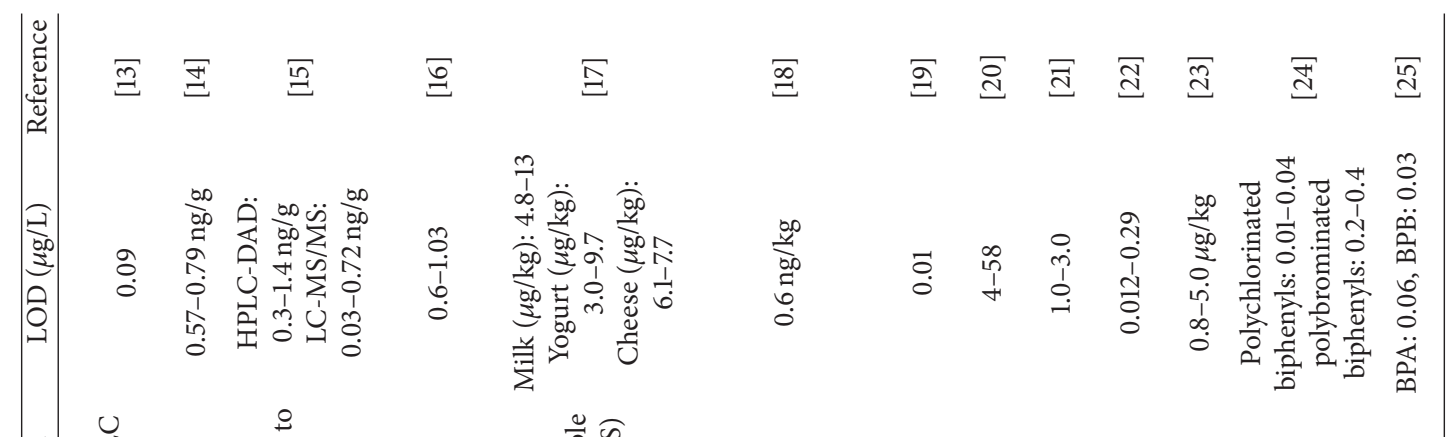

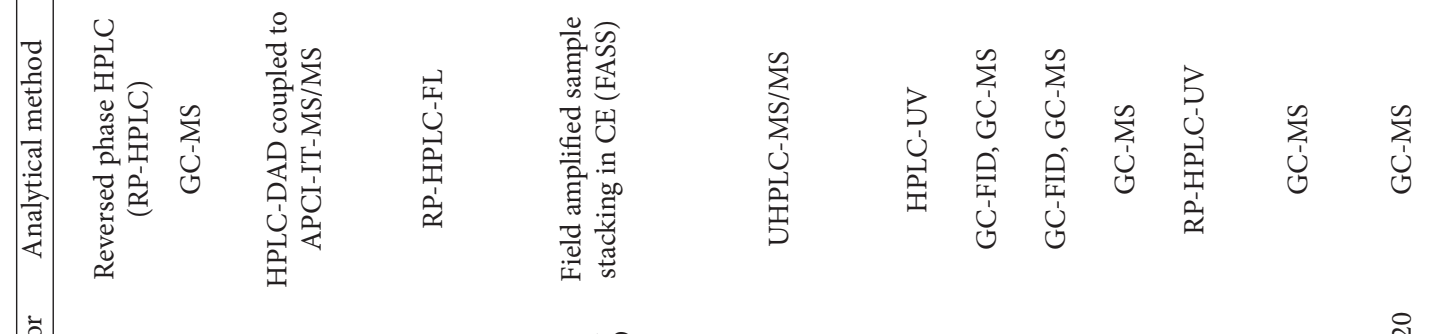

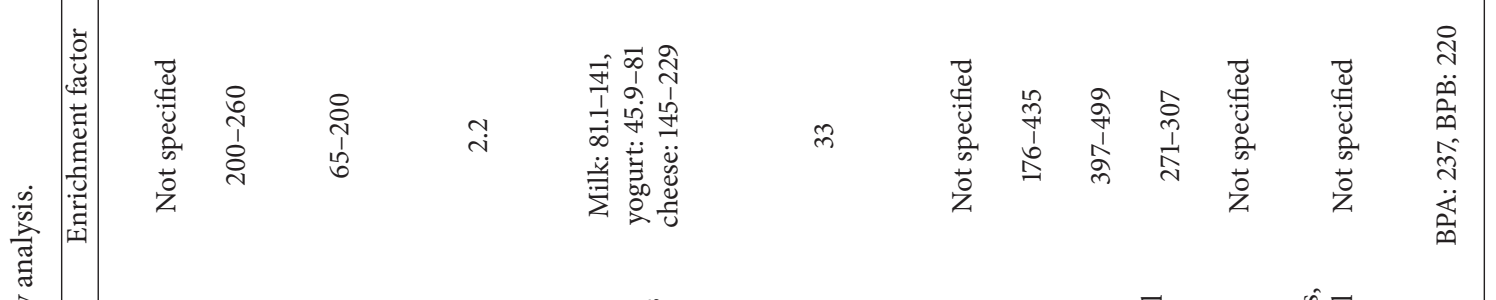

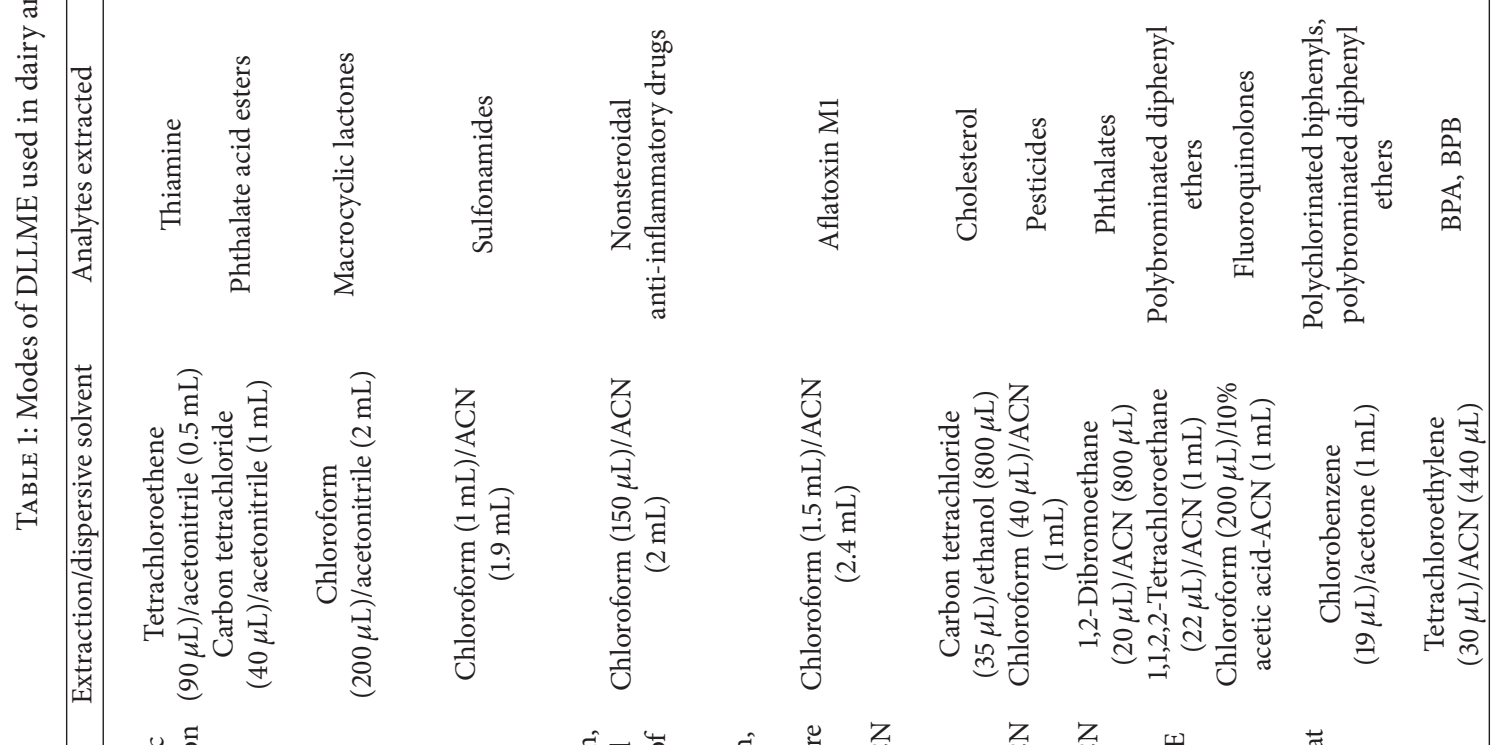

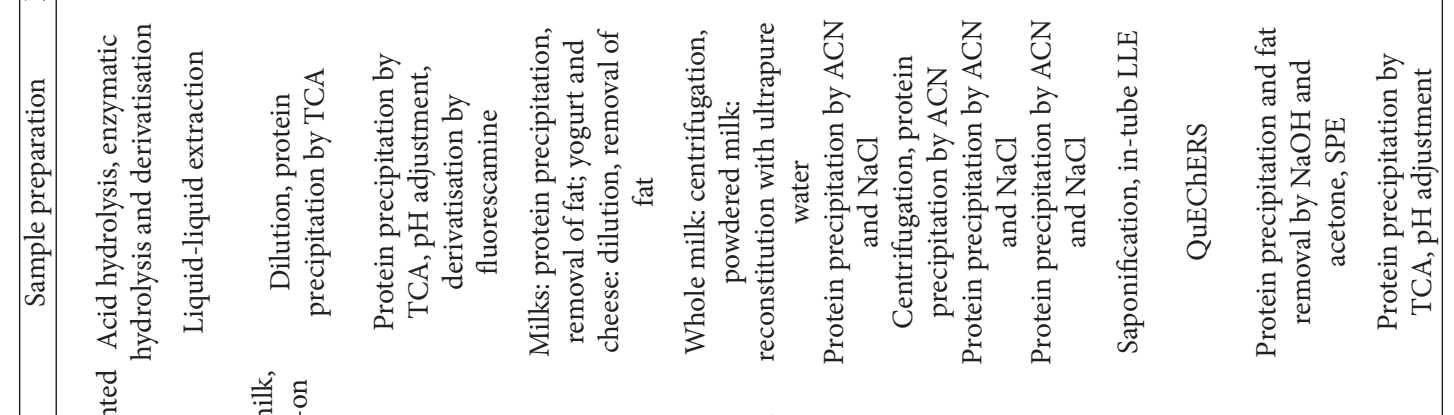

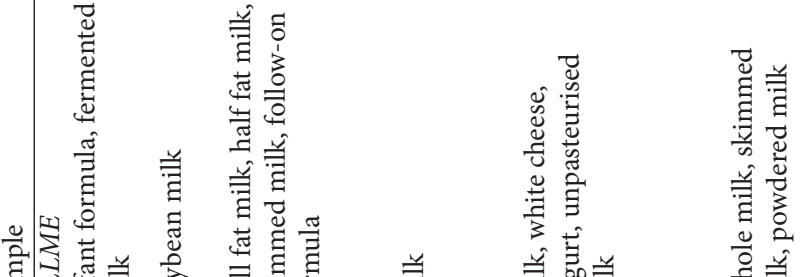




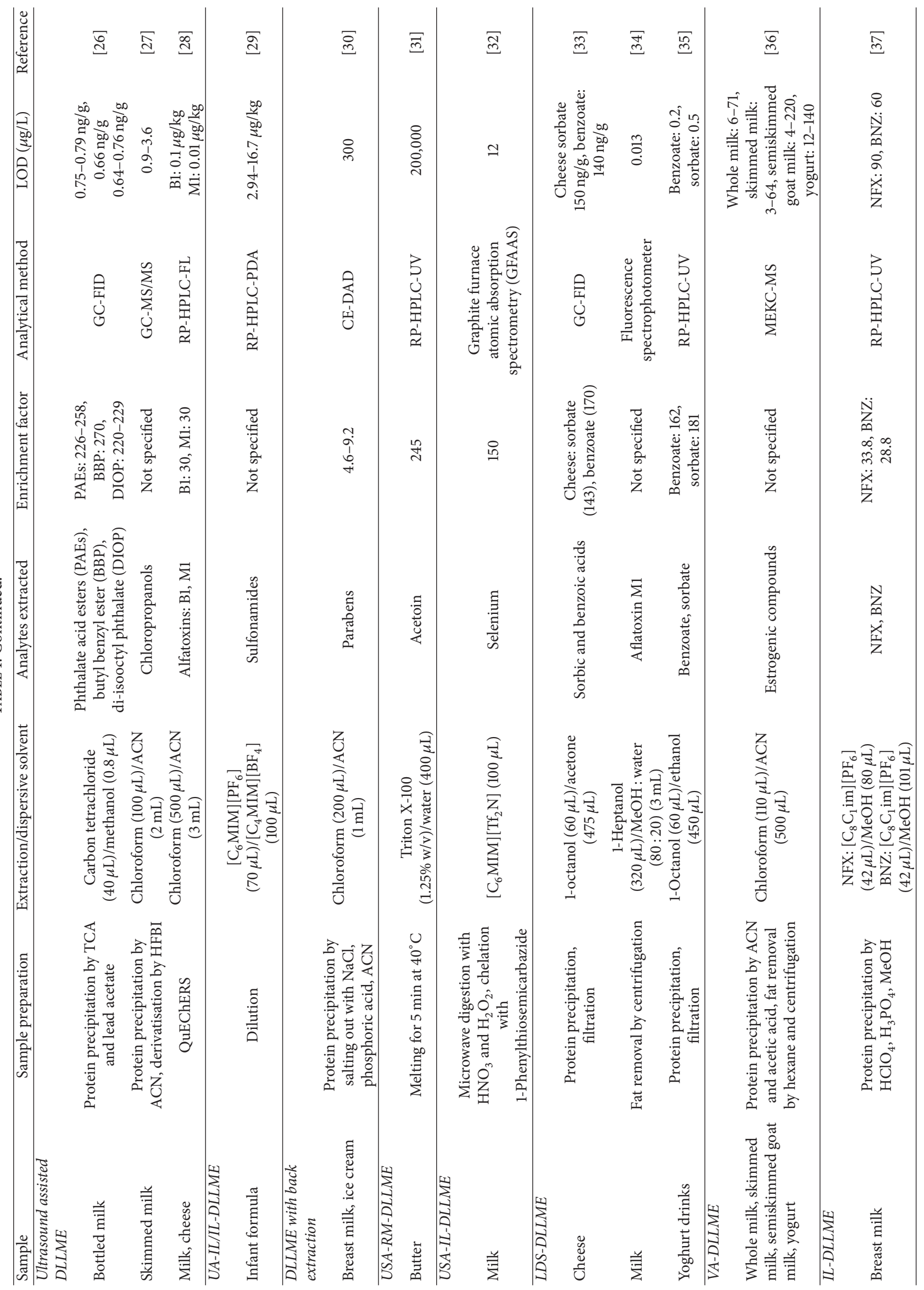


Cunha et al. expanded the range of dairy samples from milk to infant formula, while analysing bisphenol A (BPA) and bisphenol B (BPB) content using heart-cutting GC-MS [25]. The authors developed an optimised DLLME method coupled with in situ derivatisation using acetic anhydride in the presence of potassium carbonate $\left(\mathrm{K}_{2} \mathrm{CO}_{3}\right)$. After protein precipitation using trichloroacetic acid, $\mathrm{K}_{2} \mathrm{CO}_{3}$ was added until the $\mathrm{pH}$ was greater than 10; this mixture was then used as the aqueous phase in the DLLME procedure. The dispersive-extraction solvent mixture $(440 \mu \mathrm{L}$ ACN $/ 30 \mu \mathrm{L}$ tetrachloroethylene) was combined with $30 \mu \mathrm{L}$ of acetic acid as derivatisation agent and rapidly injected into the aqueous phase and the resulting cloudy suspension was allowed to react for 1 minute. Using deuterated BPA as an internal standard, recovery of BPA and BPB was found to be $114 \%$ and $68 \%$, respectively. The method was linear between 0.5 and $10 \mu \mathrm{g} \mathrm{L}^{-1}$ for both analytes and low LODs (BPA: $60.0 \mu \mathrm{g} \mathrm{L}^{-1}$, BPB: $30 \mu \mathrm{g} \mathrm{L}^{-1}$ ) were obtained corresponding to high enrichment factors (BPA: 237, BPB: 220). The method repeatability was $\leq 7 \%$ when the analytes were at a concentration of $0.2 \mu \mathrm{g} \cdot \mathrm{L}^{-1}$.

In contrast with Liu et al. [24], Han et al. combined saponification, LLE, and DLLME in the determination of PBDEs in milk using GC-MS [22]. Saponification was carried out by adding a sample of milk to $50 \% \mathrm{NaOH}$ and ethanol; this mixture was heated to $70^{\circ} \mathrm{C}$ under reflux for one hour. The saponified mixture was cooled and rinsed five times with petroleum ether. The washings were collected and centrifuged. The supernatant was dried over anhydrous sodium sulphate and evaporated to dryness under nitrogen.

The residue was reconstituted in $2 \mathrm{~mL}$ of $\mathrm{ACN}$. To carry out the DLLME procedure, $1 \mathrm{~mL}$ of the ACN solution (dispersive solvent) and $22 \mu \mathrm{L}$ of 1,1,2,2-tetrachloroethane (extraction solvent) were combined and then rapidly injected into $5 \mathrm{~mL}$ of deionized water. The cloudy solution was centrifuged and the sedimented phase was removed and dried under nitrogen. The resulting residue was dissolved in $15 \mu \mathrm{L}$ of hexane and used for GC-MS analysis. The combination of saponification, LLE, and DLLME resulted in effective matrix removal, lower LODs $\left(0.012-0.29 \mu \mathrm{g} \mathrm{L}^{-1}\right)$, and higher recoveries (83-120\%) than were reported by Liu et al. The above method also had high enrichment factors (270-307) and a short extraction time of $15 \mathrm{~min}$. This method has the potential to be applied to the analysis of other organic compounds in fatty foods.

In 2012, traditional DLLME was coupled with GC-FID and GC-MS for the analysis of several phthalate esters found in milk [21]. Proteins were precipitated and phthalate esters (dimethyl phthalate (DMP), diethyl phthalate (DEP), di-isobutyl phthalate (DIBP), di- $n$-butyl phthalate (DNBP), and di-2-ethylhexyl phthalate (DEHP)) were extracted using $\mathrm{NaCl}$ and $\mathrm{ACN}$. It was found that maximum peak area for all analytes was obtained when $0.8 \mathrm{~mL}$ of ACN (from the previous extraction step) was mixed with $20 \mu \mathrm{L}$ of $1,2-$ dibromoethane and then rapidly injected into a $8 \% \mathrm{NaCl}$ solution. Identification of analyte peaks found in GC-FID chromatograms was confirmed by GC-MS. Enrichment factors were very high for all analytes, 397-499. This optimised DLLME method was compared to other methods in the literature for the analysis of phthalate esters in milk. Although a reported LLE-LC-MS/MS method had a much lower LOD (LLE-LC-MS/MS: 0.01-0.5 $\mu \mathrm{g} \mathrm{L}^{-1}$, DLLME: $0.5-3 \mu \mathrm{g} \mathrm{L}^{-1}$ ) the extraction time was much longer (LLE-LC-MS/MS: $100 \mathrm{~min}$, DLLME: $15 \mathrm{~min}$ ).

Viñas et al. determined the concentration of thiamine in infant formula and fermented milk using traditional DLLME with HPLC fluorometric detection [13]. All samples underwent a derivatisation reaction to differentiate between thiamine and its esters. The maximum peak area was achieved by selecting $\mathrm{ACN}(500 \mu \mathrm{L})$ as dispersive solvent, tetrachloroethene $(90 \mu \mathrm{L})$ as extraction solvent, an aqueous phase with an ionic strength $(\mathrm{NaCl})$ of $24 \%$, and centrifugation for 1 minute at 4,000 rpm. The results indicated that DLLME was time-independent, as equilibrium was reached almost instantaneously. The optimised DLLME procedure resulted in lower extraction times (a few seconds) compared to a LPME method (30 min), better extraction efficiency, an LOD of $0.09 \mu \mathrm{g} \mathrm{L}^{-1}$, and linearity between 0.5 and $10 \mu \mathrm{g} \mathrm{L}^{-1}$. Recovery of thiamine in infant formula was found to be $98.7 \%$ with an RSD of $5.4 \%$.

It was 2013 before DLLME was coupled with fieldamplified sample stacking in CE, in the determination of five different nonsteroidal anti-inflammatory drugs (NSAIDs) in milk, yogurt, and cheese [17]. As with other milk samples previously mentioned, proteins were precipitated using phosphoric acid, $\mathrm{NaCl}$, and $\mathrm{ACN}$ and centrifugation. Hexane was added to the supernatant to remove any fat present; the hexane was then discarded and the ACN layer was used in the DLLME procedure. For cheese and yogurt, the samples were homogenised with $2 \mathrm{~mL}$ of deionized water and the same procedure was followed as outlined above. The results from the optimised DLLME procedure were compared to other preconcentration techniques used in the extraction of NSAIDs. The extraction time was at least five times faster than other reported methods and used at least half the amount of organic solvents.

Campillo et al. analysed several macrocyclic lactones in milk using HPLC-DAD coupled to atmospheric pressure chemical ionization in negative ion mode ion-trap tandem mass spectrometry (APCI-IT-MS/MS) [15]. Prior to DLLME, the proteins were precipitated using TCA. The maximum peak area was achieved when ACN $(2 \mathrm{~mL})$ as dispersive solvent and chloroform $(200 \mu \mathrm{L})$ as extraction solvent were used. The optimum ionic strength of the aqueous phase was obtained by adding $\mathrm{NaCl}$ to achieve a concentration of $24 \% \mathrm{w} / \mathrm{v}$. Using DAD detection, the widest linearity was $5-2500 \mathrm{ng} \mathrm{g}^{-1}$ (DOR) while the lowest LOD was $0.3 \mathrm{ng} \mathrm{g}^{-1}$ (MOX and DOR). The lowest LOD achieved by MS/MS was $0.03 \mathrm{ng} \mathrm{g}^{-1}$. LC-MS/MS detection produced higher selectivity and improved sensitivity.

Campone et al. used a Box-Behnken experimental design to optimise the DLLME procedure used to determine aflatoxin $\mathrm{M}_{1}\left(\mathrm{AFM}_{1}\right)$ in whole, skimmed, and powdered milk with UHPLC-MS/MS detection [18]. The authors also compared two different methods for protein precipitation. Firstly, acetic acid was added and then the sample was heated to $100^{\circ} \mathrm{C}$ for $3 \mathrm{~min}$ and centrifuged and aqueous supernatant was used in the DLLME procedure. This method resulted in a 
recovery of only $42.7 \%$, possibly due to proteins binding with $\mathrm{AFM}_{1}$. The second method investigated used $\mathrm{NaCl}$ and $\mathrm{ACN}$ to simultaneously precipitate proteins and extract $\mathrm{AFM}_{1}$ into the ACN. After centrifugation, the ACN supernatant was used as the dispersive solvent in the following DLLME procedure. The volumes of chloroform and $\mathrm{ACN}$ that resulted in highest recovery were $1.5 \mathrm{~mL}$ and $3.8 \mathrm{~mL}$, respectively. The mixture of extraction and dispersive solvent was rapidly injected into $5 \mathrm{~mL}$ of water. Recovery for whole, skimmed, and powdered milk was $75.3 \%, 74.2 \%$, and $73.3 \%$ with precision ranging from $1.6 \%$ to $7.6 \%$. The method was linear from 0.25 to $25 \mu \mathrm{g} \mathrm{L}^{-1}$ and had a LOD of $0.6 \mathrm{ng} \mathrm{kg}^{-1}$, which is lower than regulations (50 $\mathrm{ng} \mathrm{kg}^{-1}$ [53]).

In 2014, Arroyo-Manzanares et al. used traditional DLLME for the determination of several sulphonamides in milk; the analytes were detected by HPLC with fluorescence detection [16]. The authors also compared their optimised DLLME procedure to QuEChERS. Proteins were precipitated using TCA and then filtered. The DLLME extraction procedure was optimised using a central composite design. The optimum volumes for the extraction solvent (chloroform) and dispersive solvent $(\mathrm{ACN})$ were $1 \mathrm{~mL}$ and $1.9 \mathrm{~mL}$, respectively. DLLME resulted in lower LODs $\left(0.73-1.21 \mu \mathrm{g} \mathrm{L} \mathrm{L}^{-1}\right)$ than QuEChERS (1.15-2.73 $\mu \mathrm{g} \mathrm{L}^{-1}$ ) and higher recoveries (92.9\%$104.7 \%$ compared to $83.6 \%-97.1 \%$, when samples were spiked with sulphonamides at $\left.150 \mu \mathrm{g} \mathrm{L}^{-1}\right)$. QuEChERS did prove to be more reproducible than DLLME with lower \%RSD values of $2.9 \%-7.1 \%$ and $3.0 \%-9.7 \%$, respectively.

DLLME was coupled to QuEChERS in 2014 for the determination of six antibiotic fluoroquinolones with HPLCUV detection [23]. The dried supernatant from the QuEChERS method was resuspended in $1.0 \mathrm{~mL}$ of a $10 \%$ acetic acid-ACN mixture, combined with $200 \mu \mathrm{L}$ of chloroform and rapidly injected into $4 \mathrm{~mL}$ of deionized water. The cloudy solution was centrifuged for $5 \mathrm{~min}$ at $4,500 \mathrm{rpm}$. By coupling QuEChERS to DLLME, the authors have removed matrix interference, which is common problem with the detection of fluoroquinolones. The method shows good recovery (74.1-101.4\% for all analytes) and low LOQs (below $2.5 \mu \mathrm{g} \mathrm{kg}^{-1}$ for DAN and below $15 \mu \mathrm{g} \mathrm{kg}^{-1}$ for all other analytes).

In 2015, Alshana et al. determined the concentration of parabens in breast milk and ice cream using DLLME with back extraction before being analysed by $\mathrm{CE}$ [30]. Phosphoric acid $(100 \mu \mathrm{L}), \mathrm{ACN}(1.5 \mathrm{~mL})$, and $\mathrm{NaCl}$ solution $(0.5 \mathrm{~mL})$ were added to samples prior to vortex mixing for 1 minute and centrifugation for 3 minutes at 4,000 rpm. The ACN supernatant $(1 \mathrm{~mL})$ was then used as the dispersive solvent in the DLLME step. Chloroform $(200 \mu \mathrm{L})$ was added as the extraction solvent before the sample was made up to $8 \mathrm{~mL}$ with deionized water. The sample was vortexed for 1 minute which resulted in the formation of a cloudy solution. After centrifugation, the sedimented chloroform phase was transferred to a microtube where the analytes were back extracted into $80 \mu \mathrm{L}$ of BES for direct injection into CE. Enrichment factors for each paraben ranged from 7.0 to 10.7 and LOD values were between 100 and $200 \mu \mathrm{g} \mathrm{L}^{-1}$, while RSD values were from $0.6 \%$ to $2.3 \%$.
4.1.1. Ultrasound Assisted DLLME. Ultrasound assisted DLLME was first used on a dairy product for the determination of phthalate esters (DMP, DEP, DBP, BBP, DNOP, and DIOP) in milk using GC-FID [26]. Before UA-DLLME could take place, TCA and lead acetate were added to the milk samples. A mixture of $\mathrm{MeOH}(800 \mu \mathrm{L})$ and carbon tetrachloride $(40 \mu \mathrm{L})$ was used as the dispersive and extraction solvent, respectively. Once the cloudy solution had formed, it was placed in an ultrasonic bath for two minutes. The UADLLME method resulted in low LODs $\left(0.64-0.79 \mathrm{ng} \mathrm{g}^{-1}\right)$, high enrichment factors (220-270), and \%RSD values from 2.8 to $4.0 \%$.

In 2013, simultaneous derivatisation and UA-DLLME were developed for the determination of chlorophenols (1,3DCP, 2,3-DCP, and 3-MCPD) in milk using GC-MS [27]. Proteins were precipitated by ACN $(2 \mathrm{~mL})$, which was also used as the dispersive solvent. Both the extraction solvent, chloroform $(100 \mu \mathrm{L})$, and the derivatisation reagent, HFBI $(50 \mu \mathrm{L})$, were mixed with $\mathrm{ACN}$. After the formation of the cloudy solution, the sample was placed in an ultrasonic bath heated to $30^{\circ} \mathrm{C}$ for five minutes. This was to aid emulsion formation and to ensure that derivatisation was complete. The extraction parameters were optimised by experimental design. LODs as low as $0.9-3.6 \mu \mathrm{g} \mathrm{L}^{-1}$ were achieved along with recoveries ranging from $99 \%$ to $102 \%$.

Karaseva et al. coupled QuEChERS to UA-DLLME for the determination of aflatoxins $\mathrm{B} 1$ and $\mathrm{M} 1$ in milk and cheese samples using HPLC with fluorescence detection [28]. $\mathrm{QuEChERS}$ was used as a sample pretreatment protocol and to initially extract the aflatoxins from the milk samples. ACN $(3 \mathrm{~mL})$ and chloroform $(500 \mu \mathrm{L})$ were used as dispersive and extraction solvents, respectively. Once a cloudy solution had formed, it was placed in an ultrasonic bath for two minutes. The sedimented phase that was produced after centrifugation was dried under nitrogen. The residue was then reconstituted in ACN and subjected to HPLC analysis. The limits of detection for both $\mathrm{B} 1$ and $\mathrm{M} 1$ were $0.1 \mu \mathrm{g} / \mathrm{kg}$ and $0.01 \mu \mathrm{g} / \mathrm{kg}$, respectively. Recoveries for $\mathrm{B} 1$ for all samples were between $51.2 \%$ and $75.4 \%$, while $\mathrm{M} 1$ had recoveries between $52.5 \%$ and $72.2 \%$. Total sample preparation time was approximately 1.5 hours.

4.1.2. Low-Density Solvent DLLME. Solvents that have a density lower than water were used as extraction solvents in the determination of benzoate and sorbate in yogurt drinks [35]. Sample preparation involved protein precipitation by $\mathrm{NaOH}$, $\mathrm{H}_{2} \mathrm{SO}_{4}$, potassium hexaferrocyanide, and zinc acetate. The supernatant from the previous step was used as the aqueous phase for LDS-DLLME. Ethanol $(450 \mu \mathrm{L})$ and 1-octanol $(60 \mu \mathrm{L})$ were used as the dispersive and extraction solvents, respectively. After centrifugation of the cloudy solution, the 1-octanol was removed and injected into HPLC-UV system for analysis. The LDS-DLLME parameters were optimised by a central composite experimental design. This method was compared to several other procedures reported in the literature for the analysis of benzoate and sorbate. LODs for this method (benzoate: $0.06 \mu \mathrm{g} \mathrm{L}^{-1}$, sorbate: $0.15 \mu \mathrm{g} \mathrm{L}^{-1}$ ) were much lower than those found in other methods (benzoate: $1.22-900 \mu \mathrm{gL}^{-1}$, sorbate: $2-500 \mu \mathrm{g} \mathrm{L}^{-1}$ ). The method also 
provided good recovery of both benzoate $(91.25 \%)$ and sorbate (106\%).

Abedi et al. also determined benzoate and sorbate concentration in milk, cheese, and yogurt drinks by LDSDLLME, this time using GC-FID as the detection method [33]. Many aspects of the papers are the same: both methods are optimised by central composite design, both use similar sample pretreatment procedures, and both have found that the optimum extraction solvent is $60 \mu \mathrm{L}$ of 1-octanol. Abedi et al. have found that $475 \mu \mathrm{L}$ of acetone is the optimum dispersive solvent. The newly developed LDS-DLLME-GC-FID method showed recoveries of benzoate (103.7\%) and sorbate (88\%) that differ from the previous paper. LODs were $140 \mathrm{ng}$ $\mathrm{g}^{-1}$ and $150 \mathrm{ng}^{-1}$ for benzoate and sorbate, respectively.

In 2015, Amoli-Diva et al. coupled LDS-DLLME with vortex-assisted dispersive solid phase extraction (VA-DSPE) for the analysis of aflatoxin M1 in milk samples [34]. Once the optimised LDS-DLLME emulsion had been formed (extraction solvent: 1-heptanol; $320 \mu \mathrm{L}$, dispersive solvent: $\mathrm{MeOH} /$ water $(80: 20) ; 3 \mathrm{~mL}), 500 \mu \mathrm{L}$ of adsorbent (containing acid modified magnetic nanoparticles (MNPs)) was added and the sample was agitated on a vortex. An external magnet was applied which allowed the safe removal of supernatant. The analyte was desorbed from the adsorbent by the addition of $2 \mathrm{~mL}$ of ACN. Finally, the analyte was separated from the MNPs by magnetic decantation. The ACN eluent was evaporated to dryness and the residue was reconstituted in Triton X-100 before analysis by fluorescence spectrophotometer. The method had an LOD for aflatoxin M1 of $0.013 \mu \mathrm{g} \mathrm{L}^{-1}$, a linear range between 0.02 and $200 \mu \mathrm{g} \mathrm{L}^{-1}$, and an extraction time of $20 \mathrm{~min}$.

4.1.3. UA-RM-DLLME. Previously, all analytes mentioned have largely been nonpolar, hydrophobic compounds. Roosta et al. have developed a method using a surfactant that forms reverse micelles (Triton X-100) for the determination of acetoin, a polar compound, in butter using an ultrasound assisted-reverse micelle-DLLME procedure coupled with HPLC-UV detection [31]. The butter samples $(2 \mathrm{~g})$ were melted by heating at $40^{\circ} \mathrm{C}$ for 5 minutes before dilution with $2 \mathrm{~mL}$ of hexane and adding Triton X-100 $(1.25 \% \mathrm{w} / \mathrm{v})$. The sample was mixed by vortex for 1 minute. Distilled water $(400 \mu \mathrm{L})$ was added as a modifier and the formation of a cloudy solution was produced by placing the sample in an ultrasonic bath for 4 minutes followed by centrifugation. The extraction process was optimised by a Box-Behnken experimental design. The LOD for the developed method was found to be $200 \mu \mathrm{g} \mathrm{L}^{-1}$, while extraction recovery and repeatability were $96.40 \%$ and $2.86 \%$, respectively.

4.1.4. IL-DLLME. Room temperature ionic liquids are another alternative green extraction solvent. Recently, in 2015, an IL-DLLME procedure was developed for the determination of nifurtimox (NFX) and benznidazole (BNZ) in breast milk coupled to HPLC-UV [37]. Proteins and lipids were removed by the addition of a precipitation mixture $\left(\mathrm{HClO}_{4}, \mathrm{H}_{3} \mathrm{PO}_{4}\right.$, and methanol) followed by incubation at $80^{\circ} \mathrm{C}$ for 60 minutes. After centrifugation, the supernatant was separated from the solid material (proteins and lipids).
This process was repeated and the supernatants combined. Analysis of NFX and BNZ was carried out separately using two different IL-DLLME procedures. For NFX, a mixture of $\mathrm{NaOH}(50 \mu \mathrm{L} ; 2 \mathrm{M})$ and $\mathrm{KCl}(150 \mu \mathrm{L} ; 30 \% \mathrm{w} / \mathrm{v})$ was added to the supernatant. Then $42 \mu \mathrm{L}$ of $\left[\mathrm{C}_{6} \mathrm{C}_{1} \mathrm{im}\right]\left[\mathrm{PF}_{6}\right]$, as extraction solvent, and $80 \mu \mathrm{L}$ of $\mathrm{MeOH}$, as dispersive solvent, were rapidly injected into the above supernatant. For BNZ, a mixture of $\mathrm{NaOH}(45 \mu \mathrm{L} ; 2 \mathrm{M})$ and $\mathrm{KCl}(100 \mu \mathrm{L}$; $30 \% \mathrm{w} / \mathrm{v}$ ) was added to the supernatant obtained from the pretreatment step. Both $\left[\mathrm{C}_{6} \mathrm{C}_{1} \mathrm{im}\right]\left[\mathrm{PF}_{6}\right](42 \mu \mathrm{L})$ and $\mathrm{MeOH}$ $(101 \mu \mathrm{L})$ were mixed and rapidly injected into the above supernatant. The NFX and BNZ samples were shaken on a vortex for 6 minutes and centrifuged at 10,000 rpm for $20 \mathrm{~min}$. The extraction solvent was sedimented at the bottom of the centrifuge tube. The supernatant was removed and the extraction solvent was injected for analysis. The NFX procedure had an LOD of $290 \mu \mathrm{g} \mathrm{L}^{-1}$, a linear range from 300 to $34,400 \mu \mathrm{g} \mathrm{L}^{-1}$, and an enrichment factor of 33.8. The BNZ procedure had a LOD of $180 \mu \mathrm{gL}^{-1}$, a linear range from 200 to $29,160 \mu \mathrm{gL}^{-1}$, and an enrichment factor of 28.8.

4.1.5. UA-IL-DLLME. The use of ionic liquids as extraction solvents has been combined with US-DLLME in technique termed: UA-IL-DLLME. Tuzen and Pekiner developed an US-IL-DLLME method for the determination of selenium in milk using graphite furnace atomic absorption spectrometric detection [32]. Prior to microextraction, the $\mathrm{pH}$ of the sample was lowered to $\mathrm{pH} 2$ with dilute $\mathrm{HCl}$. Chelation of selenium was achieved through adding $0.1 \%$ 1-phenylthiosemicarbazide $(1 \mathrm{~mL})$. The extraction solvent, $\left[\mathrm{C}_{6} \mathrm{MIM}\right]\left[\mathrm{Tf}_{2} \mathrm{~N}\right](100 \mu \mathrm{L})$, was added and the sample was placed in an ultrasonic bath for 10 minutes. The resulting cloudy solution was centrifuged and, afterwards, placed on ice to increase the viscosity of the now sedimented extraction solvent. The aqueous phase was removed by simple decantation. A mixture of $\mathrm{HNO}_{3}$ and ethanol $(1: 1 \mathrm{v} / \mathrm{v})$ was added to the extraction solvent to decrease viscosity and allow for easier retrieval. The authors found that, without the use of ultrasound, recovery of selenium was below $25 \%$ and quantitative recovery was achieved when the sample was sonicated for 10 minutes. The UA-IL-DLLME method had an LOD of $0.012 \mu \mathrm{g} \mathrm{L}^{-1}$, a linear range between 0.04 and $3.0 \mu \mathrm{g} \mathrm{L}^{-1}$, a $\%$ RSD value of $4.2 \%$, and an enrichment factor of 150 .

4.1.6. UA-IL/IL-DLLME. Ionic liquids have also been used as both dispersive (hydrophilic IL) and extraction (hydrophobic IL) solvents in the same method. Gao et al. have developed a UA-IL/IL-DLLME method to determine the concentration of sulphonamides in infant formula using HPLC-PDA detection [29]. A sample of milk powder was weighed and dissolved in distilled water $\left(50^{\circ} \mathrm{C}\right)$; the ratio of infant formula to water was $1: 8$. Orthophosphoric acid $(20 \mu \mathrm{L})$ and $\left[\mathrm{C}_{6} \mathrm{MIM}\right]\left[\mathrm{BF}_{4}\right]$ $(70 \mu \mathrm{L})$, as extraction solvent, were added to the sample and intensely shaken for $5 \mathrm{~min}$. When complete, $\left[\mathrm{C}_{4} \mathrm{MIM}\right]\left[\mathrm{BF}_{4}\right]$ $(100 \mu \mathrm{L})$, as dispersive solvent, was added and the sample was transferred to an ultrasonic bath for 2 minutes. The resulting cloudy solution was then centrifuged and the sedimented extraction phase was collected. The IL was diluted 
with ACN and $0.1 \%$ formic acid to $200 \mu \mathrm{L}$ before being filtered and injected into HPLC for analysis. The optimised method was used to determine the concentration of six different sulphonamides: sulfamerazine (SMI), sulfamethizole (SMT), sulfachlopyridazine (SCP), sulfamonomethoxine (SMM), sulfamethoxazole (SMX), and sulfisoxazole (SIA). The LODs for each sulphonamide ranged from 2.94 to $16.7 \mu \mathrm{g}$ $\mathrm{kg}^{-1}$. Recovery for all the sulphonamides was all above $95 \%$ with RSD values less than $6.5 \%$.

4.1.7. VA-DLLME. D'Orazio et al. developed a VA-DLLME method to determine estrogenic compounds in milk and yogurt coupled to micellar electrokinetic chromatography with mass spectrometry [36]. The removal of proteins and fats was achieved by adding ACN $(4 \mathrm{~mL})$ and acetic acid $(100 \mu \mathrm{L})$. The sample was vortexed for 2 minutes and left in the dark for 15 minutes before centrifugation for 10 minutes at $4400 \mathrm{rpm}$. The supernatant was treated with $2 \mathrm{~mL}$ of hexane and the above vortex and centrifugation process was repeated. The aqueous layer was evaporated to $1.5 \mathrm{~mL}$ using a rotavapor $\left(40^{\circ} \mathrm{C}\right.$; $\left.180 \mathrm{mbar}\right)$. The extract was diluted to $7.5 \mathrm{~mL}$ with Milli$\mathrm{Q}$ water and $\mathrm{NaCl}$ was added $(30 \% \mathrm{w} / \mathrm{v})$. After filtration, a mixture of dispersive solvent $(\mathrm{ACN} ; 500 \mu \mathrm{L})$ and extraction solvent (chloroform; $110 \mu \mathrm{L}$ ) was added and the sample was vortexed for 2 minutes. After centrifugation, the sedimented chloroform phase was collected and evaporated to dryness, before being reconstituted in $75 \mu \mathrm{L}$ of the sample medium (11.25 mM APFO, pH 9 containing 10\% v/v MeOH) and injected into the MEKC-MS system.

\section{Conclusion}

This is the first review of the use of DLLME in dairy samples. It can be seen that the various modes of DLLME can be applied to a range of analytes in different samples, while being coupled to various analytical techniques. The review also highlights the importance of the sample pretreatment step in carrying out a successful DLLME method. With the correct sample pretreatment, DLLME can be a powerful tool in the analysis of analytes in dairy products, affording high enrichment factors while using minimal organic solvents. The technique allows the use of different analytical techniques which increases the number of potential analytes that can be tested. In general, the above modes of DLLME are both quick and easy to use, but they do have some drawbacks. Each sample can require: $\mathrm{pH}$ adjustment, filtration, or centrifugation, depending on the sample pretreatment required. This can increase total sample preparation time.

\section{Competing Interests}

The authors declare that they have no competing interests.

\section{Acknowledgments}

The authors would like to thank the Irish Research Council for funding this research under Grant no. GOIPG/2015/ 3681 .

\section{References}

[1] I. Domínguez, E. J. González, and Á. Domínguez, "Liquid extraction of aromatic/cyclic aliphatic hydrocarbon mixtures using ionic liquids as solvent: literature review and new experimental LLE data," Fuel Processing Technology, vol. 125, pp. 207216, 2014

[2] W. A. Wan Ibrahim, L. I. Abd Ali, A. Sulaiman, M. M. Sanagi, and H. Y. Aboul-Enein, "Application of solid-phase extraction for trace elements in environmental and biological samples: a review," Critical Reviews in Analytical Chemistry, vol. 44, no. 3, pp. 233-254, 2014.

[3] C. L. Arthur and J. Pawliszyn, "Solid phase microextraction with thermal desorption using fused silica optical fibers," Analytical Chemistry, vol. 62, no. 19, pp. 2145-2148, 1990.

[4] M. Mei, X. Huang, X. Yang, and Q. Luo, "Effective extraction of triazines from environmental water samples using magnetismenhanced monolith-based in-tube solid phase microextraction," Analytica Chimica Acta, vol. 937, pp. 69-79, 2016.

[5] X. Chen and N. Ye, "Graphene oxide-reinforced hollow fiber solid-phase microextraction coupled with high-performance liquid chromatography for the determination of cephalosporins in milk samples," Food Analytical Methods, vol. 9, no. 9, pp. 2452-2462, 2016.

[6] D. Fiorini, M. C. Boarelli, R. Gabbianelli, R. Ballini, and D. Pacetti, "A quantitative headspace-solid-phase microextraction-gas chromatography-flame ionization detector method to analyze short chain free fatty acids in rat feces," Analytical Biochemistry, vol. 508, pp. 12-14, 2016.

[7] M. A. Jeannot, A. Przyjazny, and J. M. Kokosa, "Single drop microextraction-development, applications and future trends," Journal of Chromatography A, vol. 1217, no. 16, pp. 23262336, 2010.

[8] M. Ghambarian, Y. Yamini, and A. Esrafili, "Developments in hollow fiber based liquid-phase microextraction: principles and applications," Microchimica Acta, vol. 177, no. 3-4, pp. 271-294, 2012.

[9] A. Zgoła-Grześkowiak and T. Grześkowiak, "Dispersive liquidliquid microextraction," TrAC-Trends in Analytical Chemistry, vol. 30, no. 9, pp. 1382-1399, 2011.

[10] J. López-Darias, M. Germán-Hernández, V. Pino, and A. M. Afonso, "Dispersive liquid-liquid microextraction versus single-drop microextraction for the determination of several endocrine-disrupting phenols from seawaters," Talanta, vol. 80, no. 5, pp. 1611-1618, 2010.

[11] G. Shen and K. L. Hian, "Hollow fiber-protected liquid-phase microextraction of triazine herbicides," Analytical Chemistry, vol. 74, no. 3, pp. 648-654, 2002.

[12] S. King, J. S. Meyer, and A. R. J. Andrews, "Screening method for polycyclic aromatic hydrocarbons in soil using hollow fiber membrane solvent microextraction," Journal of Chromatography A, vol. 982, no. 2, pp. 201-208, 2002.

[13] P. Viñas, I. López-García, M. Bravo-Bravo, M. Briceño, and M. Hernández-Córdoba, "Dispersive liquid-liquid microextraction coupled to liquid chromatography for thiamine determination in foods," Analytical and Bioanalytical Chemistry, vol. 403, no. 4, pp. 1059-1066, 2012.

[14] S. Bai, X. Wang, F. Hu, T. Wang, P. Cheng, and Z. Zhou, "Determination of phthalate acid esters in soybean milk using dispersive liquid-liquid microextraction coupled with gas chromatography and mass spectrometric detection," Analytical Methods, vol. 6, no. 18, pp. 7361-7366, 2014. 
[15] N. Campillo, P. Viñas, G. Férez-Melgarejo, and M. HernándezCórdoba, "Dispersive liquid-liquid microextraction for the determination of macrocyclic lactones in milk by liquid chromatography with diode array detection and atmospheric pressure chemical ionization ion-trap tandem mass spectrometry," Journal of Chromatography A, vol. 1282, pp. 20-26, 2013.

[16] N. Arroyo-Manzanares, L. Gámiz-Gracia, and A. M. GarcíaCampaña, "Alternative sample treatments for the determination of sulfonamides in milk by HPLC with fluorescence detection," Food Chemistry, vol. 143, pp. 459-464, 2014.

[17] U. Alshana, N. G. Göğer, and N. Ertaş, "Dispersive liquid-liquid microextraction combined with field-amplified sample stacking in capillary electrophoresis for the determination of nonsteroidal anti-inflammatory drugs in milk and dairy products," Food Chemistry, vol. 138, no. 2-3, pp. 890-897, 2013.

[18] L. Campone, A. L. Piccinelli, R. Celano, M. Russo, and L. Rastrelli, "Rapid analysis of aflatoxin M1 in milk using dispersive liquid-liquid microextraction coupled with ultrahigh pressure liquid chromatography tandem mass spectrometry," Analytical and Bioanalytical Chemistry, vol. 405, no. 26, pp. 8645-8652, 2013.

[19] A. Daneshfar, T. Khezeli, and H. J. Lotfi, "Determination of cholesterol in food samples using dispersive liquid-liquid microextraction followed by HPLC-UV," Journal of Chromatography B: Analytical Technologies in the Biomedical and Life Sciences, vol. 877, no. 4, pp. 456-460, 2009.

[20] M. A. Farajzadeh, D. Djozan, M. R. A. Mogaddam, and M. Bamorowat, "Extraction and preconcentration technique for triazole pesticides from cow milk using dispersive liquid-liquid microextraction followed by GC-FID and GC-MS determinations," Journal of Separation Science, vol. 34, no. 11, pp. 13091316, 2011.

[21] M. A. Farajzadeh, D. Djozan, M. Reza, A. Mogaddam, and J. Norouzi, "Determination of phthalate esters in cow milk samples using dispersive liquid-liquid microextraction coupled with gas chromatography followed by flame ionization and mass spectrometric detection," Journal of Separation Science, vol. 35, no. 5-6, pp. 742-749, 2012.

[22] Y. Han, X. Jia, T. Duan, and H. Chen, "Combination of saponification with in-tube liquid-liquid extraction and dispersive liquid-liquid microextraction for determination of polybrominated diphenyl ethers in whole milk by gas chromatographymass spectrometry," Analytical Methods, vol. 3, no. 4, pp. 842848, 2011.

[23] R. Karami-Osboo, M. Hossein Shojaee, R. Miri, F. Kobarfard, and K. Javidnia, "Simultaneous determination of six fluoroquinolones in milk by validated QuEChERS-DLLME HPLCFLD," Analytical Methods, vol. 6, no. 15, pp. 5632-5638, 2014.

[24] X. Liu, A. Zhao, A. Zhang et al., "Dispersive liquid-liquid microextraction and gas chromatography-mass spectrometry determination of polychlorinated biphenyls and polybrominated diphenyl ethers in milk," Journal of Separation Science, vol. 34, no. 9, pp. 1084-1090, 2011.

[25] S. C. Cunha, C. Almeida, E. Mendes, and J. O. Fernandes, "Simultaneous determination of bisphenol A and bisphenol B in beverages and powdered infant formula by dispersive liquidliquid micro-extraction and heart-cutting multidimensional gas chromatography-mass spectrometry," Food Additives and Contaminants Part A: Chemistry, Analysis, Control, Exposure and Risk Assessment, vol. 28, no. 4, pp. 513-526, 2011.

[26] H. Yan, X. Cheng, and B. Liu, "Simultaneous determination of six phthalate esters in bottled milks using ultrasound-assisted dispersive liquid-liquid microextraction coupled with gas chromatography," Journal of Chromatography B: Analytical Technologies in the Biomedical and Life Sciences, vol. 879, no. 25, pp. 2507-2512, 2011.

[27] A. M. Carro, P. González, and R. A. Lorenzo, "Simultaneous derivatization and ultrasound-assisted dispersive liquid-liquid microextraction of chloropropanols in soy milk and other aqueous matrices combined with gas-chromatography-mass spectrometry," Journal of Chromatography A, vol. 1319, pp. 3545, 2013.

[28] N. M. Karaseva, V. G. Amelin, and A. V. Tret'Yakov, "QuEChERS coupled to dispersive liquid-liquid microextraction for the determination of aflatoxins B1 and M1 in dairy foods by HPLC," Journal of Analytical Chemistry, vol. 69, no. 5, pp. 461-466, 2014.

[29] S. Gao, X. Yang, W. Yu, Z. Liu, and H. Zhang, "Ultrasoundassisted ionic liquid/ionic liquid-dispersive liquid-liquid microextraction for the determination of sulfonamides in infant formula milk powder using high-performance liquid chromatography," Talanta, vol. 99, pp. 875-882, 2012.

[30] U. Alshana, N. Ertaş, and N. G. Göğera, "Determination of parabens in human milk and other food samples by capillary electrophoresis after dispersive liquid-liquid microextraction with back-extraction," Food Chemistry, vol. 181, pp. 1-8, 2015.

[31] M. Roosta, M. Ghaedi, and A. Daneshfar, "Optimisation of ultrasound-assisted reverse micelles dispersive liquid-liquid micro-extraction by Box-Behnken design for determination of acetoin in butter followed by high performance liquid chromatography," Food Chemistry, vol. 161, pp. 120-126, 2014.

[32] M. Tuzen and O. Z. Pekiner, "Ultrasound-assisted ionic liquid dispersive liquid-liquid microextraction combined with graphite furnace atomic absorption spectrometric for selenium speciation in foods and beverages," Food Chemistry, vol. 188, pp. 619-624, 2015.

[33] A.-S. Abedi, A. Mohammadi, E. Azadniya, A. M. Mortazavian, and R. Khaksar, "Simultaneous determination of sorbic and benzoic acids in milk products using an optimised microextraction technique followed by gas chromatography," Food Additives and Contaminants-Part A Chemistry, Analysis, Control, Exposure and Risk Assessment, vol. 31, no. 1, pp. 21-28, 2014.

[34] M. Amoli-Diva, Z. Taherimaslak, M. Allahyari, K. Pourghazi, and M. H. Manafi, "Application of dispersive liquid-liquid microextraction coupled with vortex-assisted hydrophobic magnetic nanoparticles based solid-phase extraction for determination of aflatoxin $\mathrm{M} 1$ in milk samples by sensitive micelle enhanced spectrofluorimetry," Talanta, vol. 134, pp. 98-104, 2015.

[35] M. Kamankesh, A. Mohammadi, Z. M. Tehrani, R. Ferdowsi, and H. Hosseini, "Dispersive liquid-liquid microextraction followed by high-performance liquid chromatography for determination of benzoate and sorbate in yogurt drinks and method optimization by central composite design," Talanta, vol. 109, pp. 46-51, 2013.

[36] G. D’Orazio, M. Asensio-Ramos, J. Hernández-Borges, M. Á. Rodríguez-Delgado, and S. Fanali, "Evaluation of the combination of a dispersive liquid-liquid microextraction method with micellar electrokinetic chromatography coupled to mass spectrometry for the determination of estrogenic compounds in milk and yogurt," Electrophoresis, vol. 36, no. 4, pp. 615-625, 2015.

[37] J. M. Padrõ, R. B. Pellegrino Vidal, R. N. Echevarria, A. N. Califano, and M. R. Reta, "Development of an ionic-liquidbased dispersive liquid-liquid microextraction method for the 
determination of antichagasic drugs in human breast milk: optimization by central composite design," Journal of Separation Science, vol. 38, no. 9, pp. 1591-1600, 2015.

[38] M. B. Melwanki and M.-R. Fuh, "Dispersive liquid-liquid microextraction combined with semi-automated in-syringe back extraction as a new approach for the sample preparation of ionizable organic compounds prior to liquid chromatography," Journal of Chromatography A, vol. 1198-1199, no. 1-2, pp. 1-6, 2008.

[39] L. Kocúrová, I. S. Balogh, J. Šandrejová, and V. Andruch, "Recent advances in dispersive liquid-liquid microextraction using organic solvents lighter than water. A review," Microchemical Journal, vol. 102, pp. 11-17, 2012.

[40] M. A. Farajzadeh and M. R. A. Mogaddam, "Air-assisted liquidliquid microextraction method as a novel microextraction technique; Application in extraction and preconcentration of phthalate esters in aqueous sample followed by gas chromatographyflame ionization detection," Analytica Chimica Acta, vol. 728, pp. 31-38, 2012.

[41] C. A. Barrett, D. A. Orban, S. E. Seebeck, L. E. Lowe, and J. E. Owens, "Development of a low-density-solvent dispersive liquid-liquid microextraction with gas chromatography and mass spectrometry method for the quantitation of tetrabromobisphenol-A from dust," Journal of Separation Science, vol. 38, no. 14, pp. 2503-2509, 2015.

[42] P. Viñas, N. Campillo, and V. Andruch, "Recent achievements in solidified floating organic drop microextraction," TrACTrends in Analytical Chemistry, vol. 68, pp. 48-77, 2015.

[43] A. Rahimi and P. Hashemi, "Development of a dispersive liquidliquid microextraction method based on solidification of a floating organic drop for the determination of beta-carotene in human serum," Journal of Analytical Chemistry, vol. 69, no. 4, pp. 352-356, 2014.

[44] K. Seebunrueng, Y. Santaladchaiyakit, and S. Srijaranai, "Vortex-assisted low density solvent liquid-liquid microextraction and salt-induced demulsification coupled to high performance liquid chromatography for the determination of five organophosphorus pesticide residues in fruits," Talanta, vol. 132, pp. 769-774, 2015.

[45] M.-I. Leong, M.-R. Fuh, and S.-D. Huang, "Beyond dispersive liquid-liquid microextraction," Journal of Chromatography A, vol. 1335, pp. 2-14, 2014.

[46] G. Lasarte-Aragonés, R. Lucena, S. Cárdenas, and M. Valcárcel, "Effervescence assisted dispersive liquid-liquid microextraction with extractant removal by magnetic nanoparticles," Analytica Chimica Acta, vol. 807, pp. 61-66, 2014.

[47] Z.-G. Shi and H. K. Lee, "Dispersive liquid-liquid microextraction coupled with dispersive $\mu$-solid-phase extraction for the fast determination of polycyclic aromatic hydrocarbons in environmental water samples," Analytical Chemistry, vol. 82, no. 4, pp. 1540-1545, 2010.

[48] A. Daneshfar and T. Khezeli, "Cloud point-dispersive liquidliquid microextraction for extraction of organic acids from biological samples," Journal of Surfactants and Detergents, vol. 17, no. 6, pp. 1259-1267, 2014.

[49] M. J. Trujillo-Rodríguez, P. Rocío-Bautista, V. Pino, and A. M. Afonso, "Ionic liquids in dispersive liquid-liquid microextraction," TrAC-Trends in Analytical Chemistry, vol. 51, pp. 87-106, 2013.

[50] L. Campone, A. L. Piccinelli, R. Celano, and L. Rastrelli, "PHcontrolled dispersive liquid-liquid microextraction for the analysis of ionisable compounds in complex matrices: case study of ochratoxin A in cereals," Analytica Chimica Acta, vol. 754, pp. 61-66, 2012.

[51] P. Viñas, N. Campillo, I. López-García, and M. HernándezCórdoba, "Dispersive liquid-liquid microextraction in food analysis. A critical review Microextraction Techniques," Analytical and Bioanalytical Chemistry, vol. 406, no. 8, pp. 2067-2099, 2014.

[52] M. A. Farajzadeh, S. E. Seyedi, M. S. Shalamzari, and M. Bamorowat, "Dispersive liquid-liquid microextraction using extraction solvent lighter than water," Journal of Separation Science, vol. 32, no. 18, pp. 3191-3200, 2009.

[53] The Commission of the European Communities, "Commission Regulation (EC) 1881/2006," Official Journal of the European Union, vol. 364, pp. 5-24, 2006. 

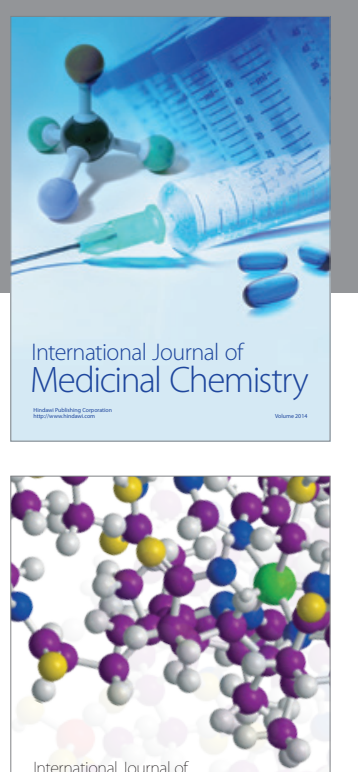

Carbohydrate Chemistry

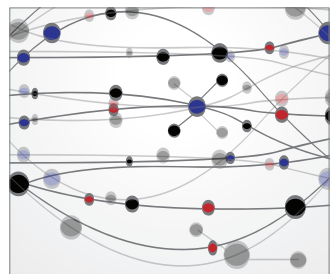

The Scientific World Journal
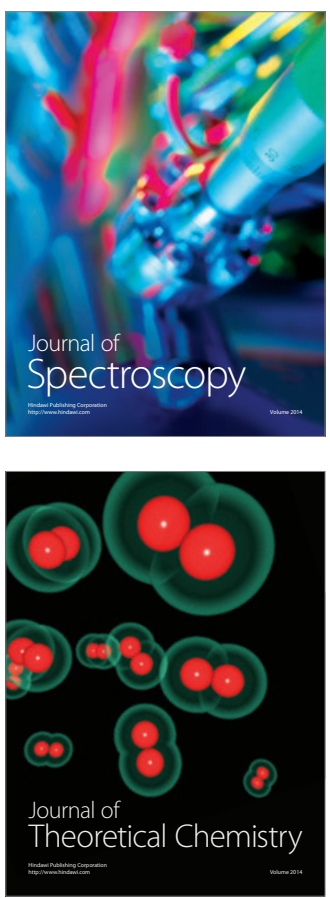
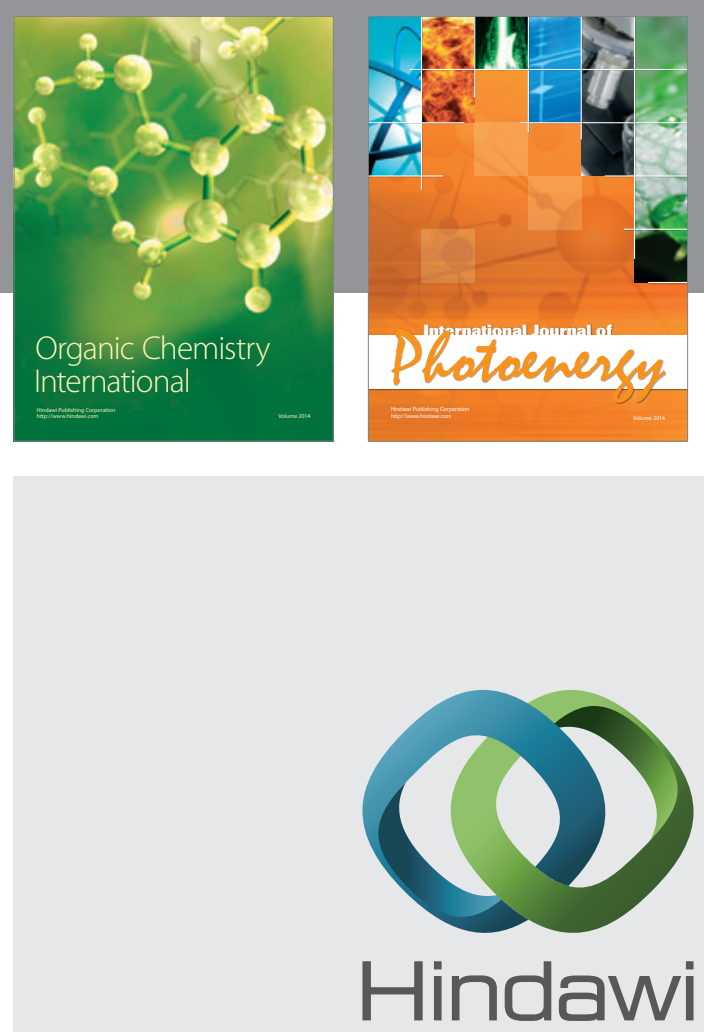

Submit your manuscripts at

http://www.hindawi.com

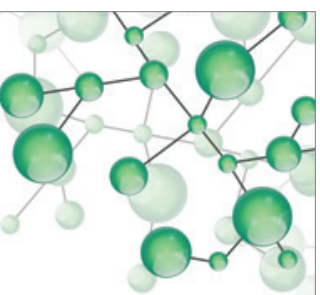

International Journal of

Inorganic Chemistry

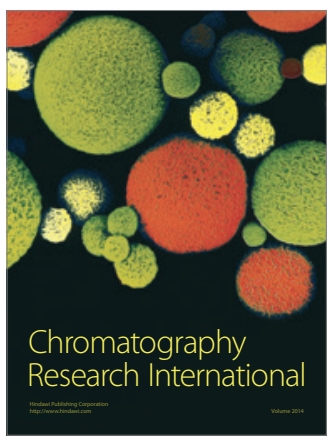

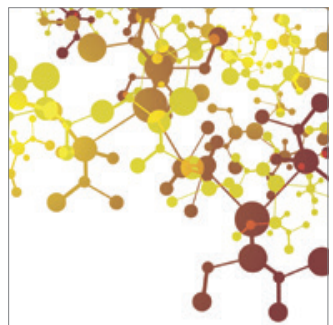

Applied Chemistry
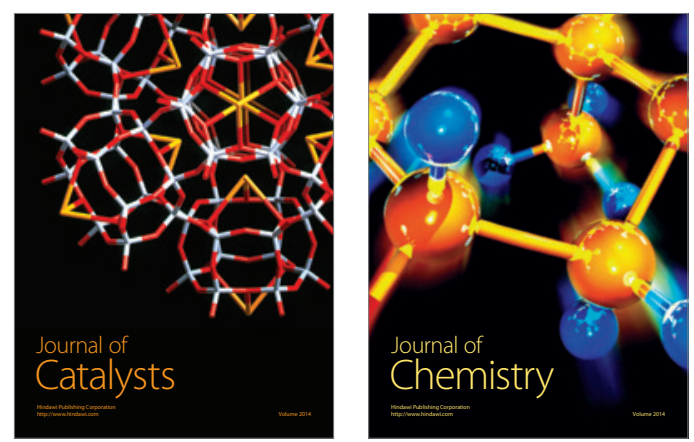
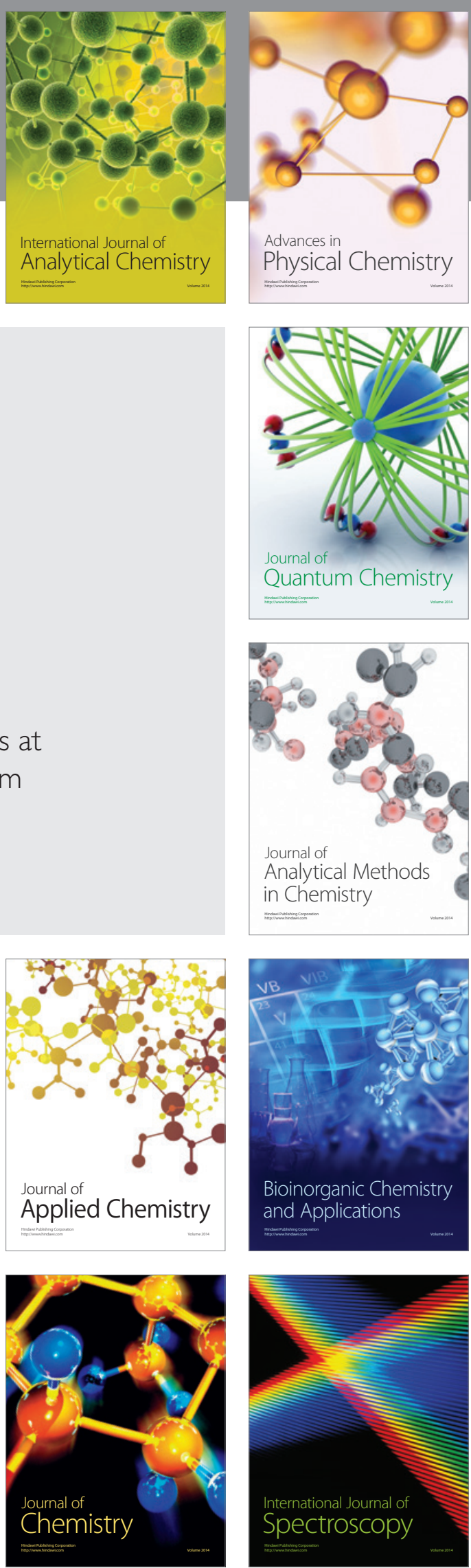